\title{
Avaliação pela técnica semiautomática de produção de gases das silagens de quatro genótipos de girassol (Helianthus annuus) (Rumbosol 91, Victoria 627, Victoria 807 e Mycogen 93338)
}

[Evaluation of four sunflower (Helianthus annuus) genotypes (Rumbosol 91, Victoria 627, Victoria 807, and Mycogen 93338) silages by semi-automated in vitro gas production technique]

D.G. Jayme ${ }^{1}$, L.C. Gonçalves ${ }^{2}$, R.M. Maurício ${ }^{3}$, J.A.S. Rodrigues ${ }^{4}$, N.M. Rodriguez ${ }^{2}$, A.L.C.C. Borges ${ }^{2}$, I. Borges ${ }^{2}$, E.O.S. Saliba ${ }^{2}$, D.A.A. Pires ${ }^{5}$, R. Guimarães Júnior ${ }^{6}$, C.G. Jayme ${ }^{7}$, L.G.R. Pereira ${ }^{8}$

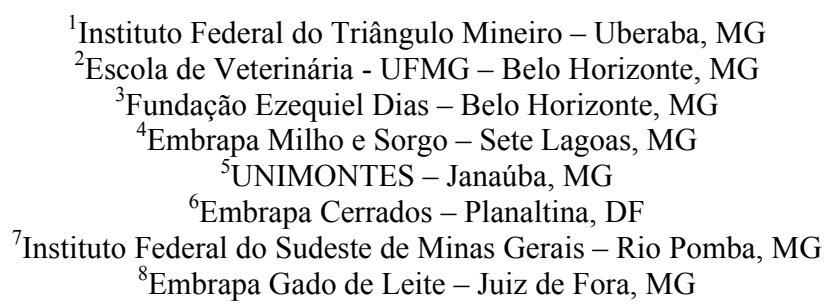

\section{RESUMO}

Foram avaliadas as silagens de quatro genótipos de girassol (Helianthus annuus) (Rumbosol 91, Victoria 627, Victoria 807 e Mycogen 93338), pela técnica semiautomática de produção de gases. $\mathrm{O}$ delineamento experimental utilizado foi o de blocos ao acaso, em esquema de parcelas subdivididas, sendo as médias comparadas pelo teste SNK $(\mathrm{p}<0,05)$. O genótipo Rumbosol 91 apresentou a maior produção acumulativa de gases para o tempo de 96 horas de incubação com valor de $128,47 \mathrm{~mL} / \mathrm{g}$ de MS, e o menor valor foi observado para o genótipo Victoria 807 com 92,88. Não foram observadas diferenças entre os valores de degradabilidade da matéria seca (DMS) para as silagens avaliadas nos diferentes tempos. O potencial máximo de produção de gases variou de 91,67 para o genótipo Victoria 807 a 125,46mL/g de MS para a silagem do genótipo Rumbosol 91. O genótipo Rumbosol 91 apresentou a maior DMS para as taxas de passagem de 2 e $5 \%$ com valores de 46,39 e 43,26\%. O maior valor para taxa de passagem (8\%) foi observado para o genótipo Victoria 627 . As silagens dos genótipos Rumbosol 91 e Victoria 627 mostraram destacado potencial para produção de gases e taxa de produção de gases.

Palavras-chave: girassol, Helianthus annuus, fermentação, produção de gases, valor nutritivo

\section{ABSTRACT}

Four silages from distinct sunflower (Helianthus annuus) genotypes (Rumbosol 91, Victoria 627, 807 Victoria, and Mycogen 93338) were evaluated by semi-automated in vitro gas production technique in a completely random block design in a split plot scheme. The means were compared by the SNK test $(P<0.05)$. Rumbosol 91 genotype showed the highest cumulative gas production after 96 hours of incubation, reaching $128.47 \mathrm{~mL} / \mathrm{g}$ of dry matter (DM), and the lowest value, $92.88 \mathrm{~mL} / \mathrm{g}$, was observed for Victoria 807 genotype. No differences between silage dry matter digestibility (DMD) values at different times were observed $(P>0.05)$. Maximum potential gas production ranged from 91.67 for Victoria 807 to $125.46 \mathrm{~mL} / \mathrm{g}$ of DM Rumbosol 91. Genotype Rumbosol 91 showed the highest DMD for fermentation rate of 2 (46.39\%) and 5\% (43.26\%), and the highest values for fermentation rate of 8\% was observed for Victoria 627 genotype. Silages from Rumbosol 91 and Victoria 627 genotypes showed outstanding potential of gases production and rate of gases production.

Keywords: sunflower, Helianthus annuus, fermentation, gas production, nutritive value

Recebido em 26 de fevereiro de 2009

Aceito em 23 de novembro de 2009

E-mail: diogogj@gmail.com 


\section{INTRODUÇÃO}

O girassol (Helianthus annuus L.) apresenta-se como planta alternativa para a ensilagem por mostrar fácil desenvolvimento em áreas de climas temperados, subtropical e tropical e maior tolerância à deficiência hídrica e geadas leves, comparada a outros cultivares de milho e sorgo (Gonçalves et al., 2000).

Os ensaios in vivo que envolvem produção animal e digestibilidade são os métodos mais precisos para determinar o valor nutricional dos alimentos. Entretanto, os mesmos requerem considerável uso de animais, alimentos, mão de obra, tempo e alto custo financeiro. Como consequência, várias técnicas in vitro foram desenvolvidas para viabilizar o estudo nutricional de alimentos. As técnicas in vitro que utilizam microrganismos e/ou enzimas que reproduzam as condições do trato digestivo dos ruminantes, pela simplicidade de execução, baixo custo, acurácia e alta relação com dados obtidos in vivo têm se tornado cada vez mais populares (Williams, 2000). O método de digestibilidade de duplo estágio proposto por Tilley e Terry (1963) é um dos mais utilizados para avaliação da digestibilidade de forragens e é considerado muito preciso para predizer o valor energético do alimento (Minson, 1990), porém esse método apresenta a limitação de não fornecer informações sobre a dinâmica da fermentação, ou seja, a taxa de degradação de determinado alimento. Na última década, a técnica de produção de gases vem sendo amplamente utilizada nos estudos de digestibilidade de forrageiras (Maurício et al.,
2003; Guimarães Jr. et al., 2008). Essa metodologia é similar a outros procedimentos de digestibilidade in vitro que utilizam substrato moído, meio de cultura anaeróbico e inóculo microbiano proveniente do líquido ruminal. O substrato é suspenso no meio anaeróbico, mantido a $39^{\circ} \mathrm{C}$, e o fluido ruminal fresco é adicionado como inóculo. A produção de gases da fermentação é registrada e interpretada como medida indireta da degradabilidade, o que possibilita a descrição da cinética de fermentação (Williams, 2000). A técnica in vitro semiautomática de produção de gases (Maurício et al., 1999), que utiliza um transdutor de pressão para medição da produção de gases, pode ser a metodologia adequada para este propósito, pois possibilita a avaliação de grande número de substratos, tem baixo custo, alta repetibilidade e oferece a possibilidade de descrição da cinética da fermentação no rúmen, estimando a taxa e a extensão da degradação.

O objetivo deste trabalho foi, por meio da metodologia de avaliação de produção de gases, plotar as curvas de fermentação, calcular os parâmetros de fermentação e estimar os valores de degradação da matéria seca das silagens de quatro genótipos de girassol (Helianthus annuus).

\section{MATERIAL E MÉTODOS}

Foram utilizadas nesse experimento silagens de girassol dos genótipos Rumbosol 91, Victoria 627, Victoria 807 e Mycogen 93338. A composição química e os valores de energia dos genótipos usados são apresentados na Tab. 1.

Tabela 1. Composição química (em \% da MS) e valores de energia bruta (Mcal $/ \mathrm{kg}$ ) das silagens de girassol avaliadas

\begin{tabular}{lccccccccc}
\hline Material & \%MS & \%PB & \%FDN & \%FDA & \%HEM & \%CEL & \%Lig & \%EE & EB(Mcal/kg) \\
\hline Rumbosol 91 & 31,20 & 8,72 & 50,39 & 24,04 & 26,34 & 16,30 & 7,75 & 10,68 & 4,79 \\
Victoria 627 & 36,88 & 8,09 & 44,11 & 27,98 & 16,12 & 19,11 & 8,87 & 12,42 & 4,71 \\
Victoria 807 & 28,62 & 8,93 & 51,88 & 27,83 & 24,05 & 20,56 & 7,27 & 17,21 & 5,00 \\
Mycogen 93338 & 22,80 & 9,16 & 47,35 & 32,29 & 15,06 & 20,66 & 11,64 & 13,02 & 4,70 \\
\hline
\end{tabular}

MS: matéria seca; PB: proteína bruta; FDN: fibra detergente neutro; FDA: fibra detergente ácido; HEM: hemicelulose; CEL: celulose; Lig: lignina; EE: extrato etéreo; EB: energia bruta

Um grama de amostra foi adicionado aos frascos de fermentação $(160 \mathrm{~mL})$ previamente injetados com $\mathrm{CO}_{2}$. Foram utilizados três frascos por tratamento. Frascos contendo somente líquido ruminal e meio de cultura (tampão) foram usados como controle. Para cada frasco, foram adicionados manualmente $90 \mathrm{~mL}$ de meio de cultura (Theodorou et al., 1994). Os frascos foram vedados com rolhas de silicone $(14 \mathrm{~mm}) \mathrm{e}$ selados com anilhas de alumínio. Para evitar que 
qualquer tipo de fermentação ocorresse, os frascos foram mantidos a $4^{\circ} \mathrm{C}$ durante a noite. Antes da inoculação, os frascos foram mantidos, durante cinco horas, em estufa a $39^{\circ} \mathrm{C}$. A inoculação foi feita com líquido ruminal, obtido de três ovinos machos sem raça definida, fistulados, mantido em dieta à base de volumoso (silagem de sorgo) à vontade e $200 \mathrm{~g}$ de concentrado comercial $(20 \%$ de PB) por dia. O líquido ruminal foi retirado e armazenado em garrafas térmicas previamente aquecidas. $\mathrm{O}$ líquido ruminal foi filtrado através de sacolas de dakron $(44 \mu)$ sob injeção contínua de $\mathrm{CO}_{2}$ e mantido em banho-maria a $39^{\circ} \mathrm{C}$. Utilizando-se seringa plástica, em cada frasco, foram inoculados $10 \mathrm{~mL}$ do líquido ruminal filtrado. A pressão originada pelos gases, acumulados na parte superior dos frascos, foi medida por intermédio de um transdutor de pressão ${ }^{1}$, conectado em sua extremidade a uma agulha $(0,6 \mathrm{~mm})$. As leituras de pressão foram feitas em maior frequência durante o período inicial de fermentação e reduzidas posteriormente $(2,4,6$, $8,10,12,15,19,24,30,36,48,72$ e 96h). A partir da inserção da agulha na tampa de silicone, a pressão produzida no interior dos frascos foi verificada no leitor digital.

A degrabilidade da matéria seca (DMS) foi obtida pela da porcentagem de matéria seca (MS) remanescente após 6, 12, 24, 48 e 96 horas de fermentação, por filtragem do conteúdo de cada frasco em cadinhos de porosidade 1 e posterior secagem em estufa a $100^{\circ} \mathrm{C}$ até se obter peso constante. O modelo de France et al. (1993) foi utilizado para descrever a curva de produção de gases em termos de taxa de produção de gases $(\mu)$, lag time $(\mathrm{L})$ e potencial de produção de gases (A).

O delineamento experimental foi o de parcelas subdivididas, em que os ovinos foram equivalentes aos blocos, os genótipos (Rumbosol 91, Victoria 627, Victoria 807 e Mycogen 93338) as parcelas e os tempos de incubação de $6,12,24,48$ e 96 horas às subparcelas. Para a comparação das médias de cada tratamento nos diferentes períodos de incubação, utilizou-se o teste de SNK a $5 \%$ de probabilidade. Os dados de produção cumulativa de gases (PCG) oriundos da fermentação de cada tratamento foram regredidos ao modelo de France et al. (1993):

${ }^{1}$ T443A - Bailey \& Mackey Ltd. - Birmingham, Inglaterra.

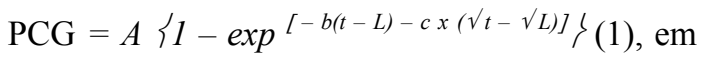
que $\mathrm{PCG}=$ produção cumulativa de gases $(\mathrm{mL})$; $A=$ assíntota ou potencial máximo de produção de gases; $\mathrm{L}=$ tempo de colonização (lag time); $b$ $\left(\mathrm{h}^{-1}\right)$ e $c\left(\mathrm{~h}^{-0,5}\right)=$ taxas fracionais constantes. Uma taxa fracional $\left(\mathrm{h}^{-1}\right)$ combinada à produção de gases $(\mu)$ foi calculada como: $\mu=b+c / 2 \sqrt{ } t(2)$, em que $\mu=$ taxa de produção de gases $\left(\mathrm{h}^{-1}\right) ; b$ e $c$ = parâmetros semelhantes ao da equação (1); $\mathrm{t}=$ tempo de incubação em horas. Os dados de DMS foram regredidos ao modelo de Ørskov e McDonald, (1979): DMS = a + b $\left(1-\exp ^{-c t}\right)$, em que $a=$ fração imediatamente degradada; $b=$ parte insolúvel mas potencialmente fermentável; $c=$ taxa constante de degradação; $t=$ tempo de incubação. As degradabilidades efetivas (DEMS) estimadas pela técnica de produção de gases empregando as taxas de passagem de 2,5 e $8 \% / \mathrm{h}$ para baixo, médio e alto consumo, respectivamente, conforme recomendações do ARC (Report..., 1984), foram calculadas pela equação (3) proposta por France et al. (1993), utilizando o software MLP (Ross, 1980). DEMS $=S_{0} e^{-k T}(1-k I) /\left(S_{0}+U_{0}\right)(3)$, em que, $k=$ taxa de passagem; $S_{0}$ e $U_{0}=$ frações inicialmente fermentáveis e frações não fermentáveis, respectivamente.

Foi feito, ainda, um estudo de regressão e correlação entre os parâmetros de DMS e PCG para a silagem de cada genótipo avaliado.

\section{RESULTADOS E DISCUSSÃO}

$\mathrm{Na}$ Tab. 2, encontram-se as PCG e as DMS das silagens de girassol, após 6, 12, 24, 48 e 96 horas de fermentação.

Não foram observadas diferenças significativas $(\mathrm{P}>0,05)$ na produção cumulativa de gases (PCG) entre os genótipos para o tempo de seis horas de incubação. Para o tempo de 12 horas, a maior PCG com 50,73mL/g de MS foi observada para o genótipo Rumbosol 91 e a menor, 33,60, para o Victoria 807. Valores intermediários e semelhantes aos demais foram encontrados para as silagens dos genótipos Victoria 627 e Mycogen 93338. Após 24 horas de fermentação, o genótipo Rumbosol 91 apresentou PCG de $98,83 \mathrm{~mL} / \mathrm{g}$ de $\mathrm{MS}$, semelhante à do Mycogen 93338 e superior a dos demais, sendo que não foram observadas diferenças entre as PCG das silagens dos genótipos Mycogen 93338 e Victoria 627. Resposta semelhante foi observada 
para o tempo de 48 horas de fermentação. O genótipo Rumbosol 91 apresentou a maior PCG para o tempo de 96 horas de incubação com valor de $128,47 \mathrm{~mL} / \mathrm{g}$ de $\mathrm{MS}$; o menor valor foi observado para o genótipo Victoria 807 com $92,88 \mathrm{~mL} / \mathrm{g}$ de $\mathrm{MS}$. Valores intermediários de PCG foram observados para os genótipos Victoria 627 e Mycogen 93338, 104,77mL/g de MS e $111,27 \mathrm{~mL} / \mathrm{g}$ de $\mathrm{MS}$, respectivamente, que foram semelhantes entre si. As diferenças observadas entre os genótipos estudados podem estar relacionadas aos diferentes teores de extrato etéreo (EE) dos materiais, já que foi observada uma tendência de menores PCG para os genótipos que apresentaram maiores concentrações de EE, uma vez que esta fração não contribui para a formação de gases durante o processo fermentativo, além das diferenças existentes nos teores de carboidratos e das frações fibrosas entre os genótipos estudados.

Tabela 2. Produções cumulativas de gases (PCG) (em $\mathrm{mL} / \mathrm{g}$ de $\mathrm{MS}$ ) corrigidas para um grama de matéria seca e degradabilidade da matéria seca (DMS) em percentagem após 6, 12, 24, 48 e 96 horas de fermentação das silagens de quatro genótipos de girassol

\begin{tabular}{cccccc}
\hline Genótipos & \multicolumn{5}{c}{ Períodos de fermentação } \\
\cline { 2 - 6 } & 6 & 12 & 24 & 48 & 96 \\
\hline PCG & $20,19 \mathrm{~A}$ & $50,73 \mathrm{~A}$ & $98,83 \mathrm{~A}$ & $116,59 \mathrm{~A}$ & $128,47 \mathrm{~A}$ \\
Rumbosol 91 & $17,48 \mathrm{~A}$ & $42,56 \mathrm{AB}$ & $78,53 \mathrm{BC}$ & $94,42 \mathrm{BC}$ & $104,77 \mathrm{~B}$ \\
Victoria 627 & $14,06 \mathrm{~A}$ & $33,60 \mathrm{~B}$ & $68,75 \mathrm{C}$ & $84,99 \mathrm{C}$ & $92,88 \mathrm{C}$ \\
Victoria 807 & $16,88 \mathrm{~A}$ & $44,86 \mathrm{AB}$ & $87,61 \mathrm{AB}$ & $102,47 \mathrm{AB}$ & $111,27 \mathrm{~B}$ \\
Mycogen 93338 & & & & & \\
DMS & $26,95 \mathrm{~A}$ & $35,56 \mathrm{~A}$ & $44,56 \mathrm{~A}$ & $44,63 \mathrm{~A}$ & $48,59 \mathrm{~A}$ \\
Rumbosol 91 & $27,80 \mathrm{~A}$ & $30,98 \mathrm{~A}$ & $41,52 \mathrm{~A}$ & $43,98 \mathrm{~A}$ & $45,48 \mathrm{~A}$ \\
Victoria 627 & $27,37 \mathrm{~A}$ & $32,84 \mathrm{~A}$ & $40,25 \mathrm{~A}$ & $44,02 \mathrm{~A}$ & $45,37 \mathrm{~A}$ \\
Victoria 807 & $29,15 \mathrm{~A}$ & $30,43 \mathrm{~A}$ & $45,63 \mathrm{~A}$ & $46,56 \mathrm{~A}$ & $46,93 \mathrm{~A}$ \\
Mycogen 93338 &
\end{tabular}

Letras iguais na coluna significam semelhança estatística ( $\mathrm{P}>0,05)(\mathrm{PCG}: \mathrm{CV}=4,62 \%$; DMS: $\mathrm{CV}=8,35 \%)$.

Não foram observadas diferenças entre os valores de DMS para as silagens avaliadas nos diferentes tempos, com valores que variaram de $27,0 \%$ a $29,2 \% ; 30,4 \%$ a $35,6 \% ; 40,3 \%$ a $45,6 \%$; $44,0 \%$ a $46,6 \%$ e $45,4 \%$ a $48,6 \%$ para os tempos de $6,12,24,48$ e 96 horas, respectivamente.

As diferenças na ordem de superioridade dos genótipos entre a PCG e DMS podem em parte ser explicadas pelo fato de que, na técnica gravimétrica (DMS), a parte solúvel do alimento pode ser considerada instantaneamente degradada, uma vez que pode escapar durante as filtragens, o que não é contemplado na $\mathrm{PCG}$, em que a fração solúvel permanece no frasco e sua cinética de fermentação pode interferir no volume de gases produzidos nos diferentes tempos de incubação. Outro fato que contribui para essas diferenças é o teor de EE dos materiais avaliados, pois, segundo Blümmel e Ørskov (1993) a produção de gases é oriunda basicamente da fermentação dos carboidratos, sendo que a contribuição das proteínas é pequena e da gordura é desprezível.

Além das fontes de variação já mencionadas, existem outras que poderiam explicar as diferenças entre ensaios. Estas estariam relacionadas aos animais doadores de inóculo ruminal, os quais, dependendo da categoria, do sexo e do estado fisiológico, poderiam apresentar diferenças no potencial fermentativo do inóculo. Schofield e Pell (1995) encontraram diferenças significativas, ao usarem diferentes inóculos de líquido ruminal, e relataram que a diferença encontrada pode ter sido em função das diferentes quantidades e espécies de microrganismos no inóculo. Jung e Varel (1988) mostraram claramente que a fonte de forragem tem efeito significativo sobre a população microbiana ruminal e subsequente atividade fibrolítica do inóculo ruminal.

As diferenças entre genótipos podem ser visualizadas na Fig. 1, na qual se observam as curvas de PCG da MS das silagens dos genótipos Rumbosol 91, Mycogen 93338, Victoria 807 e Victoria 627. Nota-se a superioridade das curvas obtidas para as silagens do genótipo Rumbosol 91, seguidas pelas curvas das silagens dos genótipos Mycogen 93338, Victoria 627 e Victoria 807. 


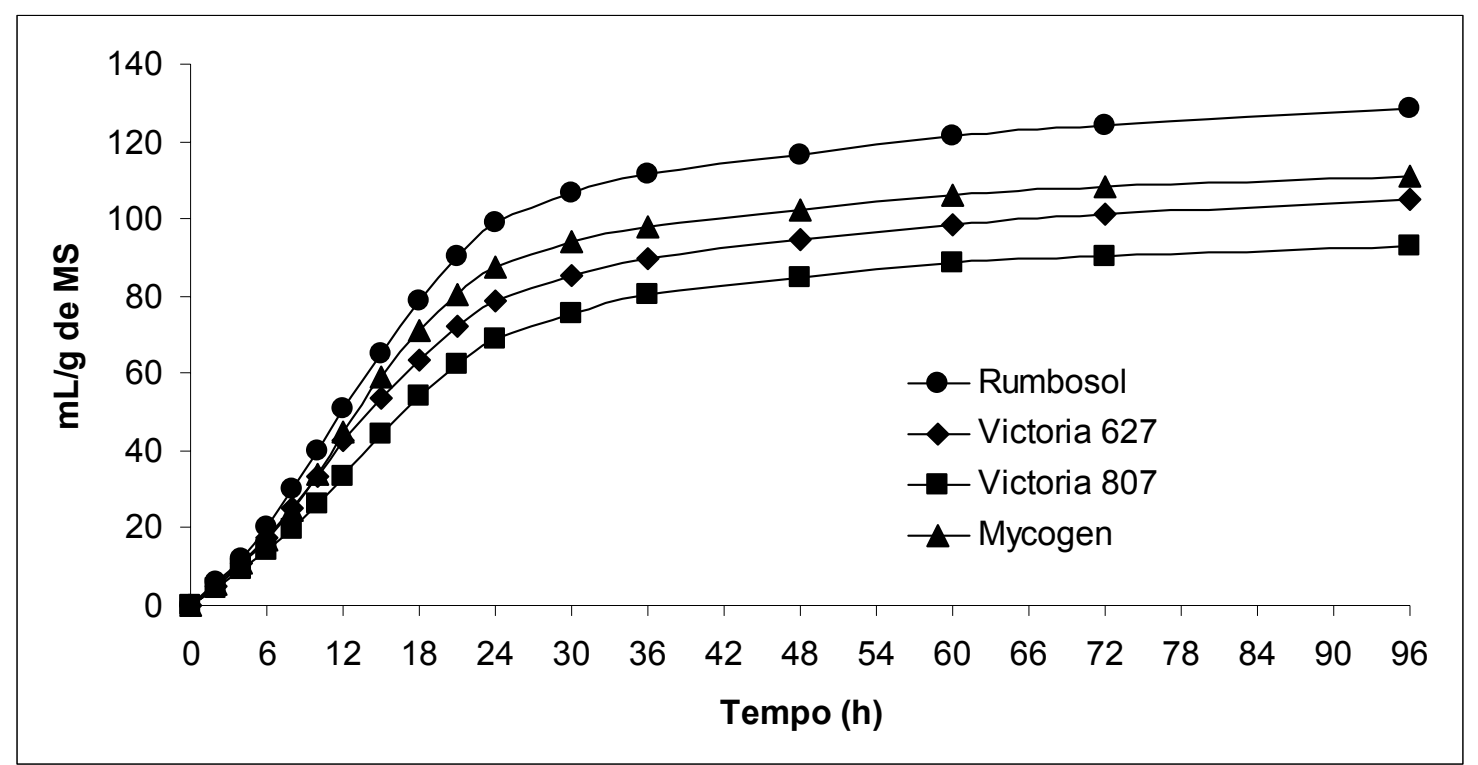

Figura 1. Produção de gases das silagens dos genótipos Rumbosol 91, Mycogen 93338, Victoria 627 e Victoria 807.

As equações de regressão a seguir representam a PCG em função do tempo de incubação:

Rumbosol 91: PCG $=125,461\left\{1-\exp ^{[-0,104(t-1,402)-(-0,248) x(\sqrt{ } t-\sqrt{ }(, 402)]}\right\} \mathrm{R}^{2}=0,992$;

Victoria 627: $\mathrm{PCG}=102,617\left\{1-\exp { }^{[-0,086(t-0,105)-(-0,150) \times(\sqrt{ } t-v 0,105)]}\right\} \mathrm{R}^{2}=0,987$;

Victoria 807: PCG $=91,670\left\{1-\exp { }^{[-0,093(t-1,395)-(-0,219) x(\sqrt{ } t-\sqrt{ }(1,395)]}\right\} \mathrm{R}^{2}=0,992$;

Mycogen 93338: PCG $=108,852\left\{1-\exp ^{[-0,118(t-1,689)-(-0,309) x(\sqrt{ } t-\sqrt{ } 1,689)]}\right\} \mathrm{R}^{2}=0,959$.

As equações a seguir representam a DMS em função do tempo de incubação:

Rumbosol 91: DMS = 6,803+40,7800 $\left(1-\exp ^{-0,102 t}\right) \mathrm{R}^{2}=0,979$;

Victoria 627: DMS $=16,683+28,443\left(1-\exp ^{-0,082 t}\right) \mathrm{R}^{2}=0,950$

Victoria 807: DMS $=18,336+27,009\left(1-\exp ^{-0,067 t}\right) \mathrm{R}^{2}=0,975$

Mycogen 93338: DMS $=15,263+32,174\left(1-\exp ^{-0,086 t}\right) \mathrm{R}^{2}=0,842$.

Todos as análises de regressão para PCG e DMS foram significativas $(\mathrm{P}<0,05)$, com altos coeficientes de determinação demonstrando incremento nas produções de gases e degradação da matéria seca de acordo com o tempo de incubação, além da adequação dos resultados de PCG e DMS aos modelos de France et al. (1993) e Ørskov e McDonald (1979), respectivamente, utilizados para todos os genótipos estudados.

A relação entre PCG e DMS nos horários de 6, $12,24,48$ e 96 horas foram significativas $(\mathrm{P}<0,01)$ e descritas pelas equações de regressão apresentadas com respectivos coeficientes de determinação $\left(\mathrm{R}^{2}\right)$ na Tab. 3

Tabela 3. Equações de regressão entre os valores de degradabilidade da matéria seca (DMS) e produção cumulativa de gases (PCG) das silagens de quatro genótipos de girassol com respectivos coeficientes de determinação $\left(\mathrm{R}^{2}\right)$

\begin{tabular}{ccc}
\hline Genótipos & Equações & $\mathrm{R}^{2}$ \\
\hline Rumbosol 91 & $\mathrm{PCG}=5,0338 \mathrm{DMS}-118,68$ & 0,95 \\
Victoria 627 & $\mathrm{PCG}=4,0677 \mathrm{DMS}-86,822$ & 0,89 \\
Victoria 807 & $\mathrm{PCG}=4,3178 \mathrm{DMS}-104,98$ & 0,98 \\
Mycogen 93338 & $\mathrm{PCG}=3,6095 \mathrm{DMS}-70,822$ & 0,80 \\
\hline
\end{tabular}


Os coeficientes de determinação $\left(\mathrm{R}^{2}\right)$ observados para os genótipos Rumbosol 91 e Victoria 807 foram elevados, demonstrando que o volume de gases produzido refletiu o processo de degradação da MS destes materiais. Fato semelhante foi observado por Pereira (2003), que avaliou, por meio da técnica de produção de gases, o genótipo de girassol M734, ensilado em quatro diferentes épocas de ensilagem $(100,107$,
114 e 121 dias após plantio). Elevadas correlações foram, também, descritas por Mould et al. (1999), ao trabalharem com silagens de milho, e por Maurício et al. (2003), ao avaliarem silagens de sorgo. A equação obtida por Maurício et al. (2003) correlacionando todos os dados da produção de gases dos quatro híbridos de sorgo com as respectivas DMS, apresentou $\mathrm{R}^{2}$ $=0,99$.

Na Figura 2, encontram-se as curvas de produção de gases por tempo de fermentação (h) das silagens dos quatro genótipos de girassol.

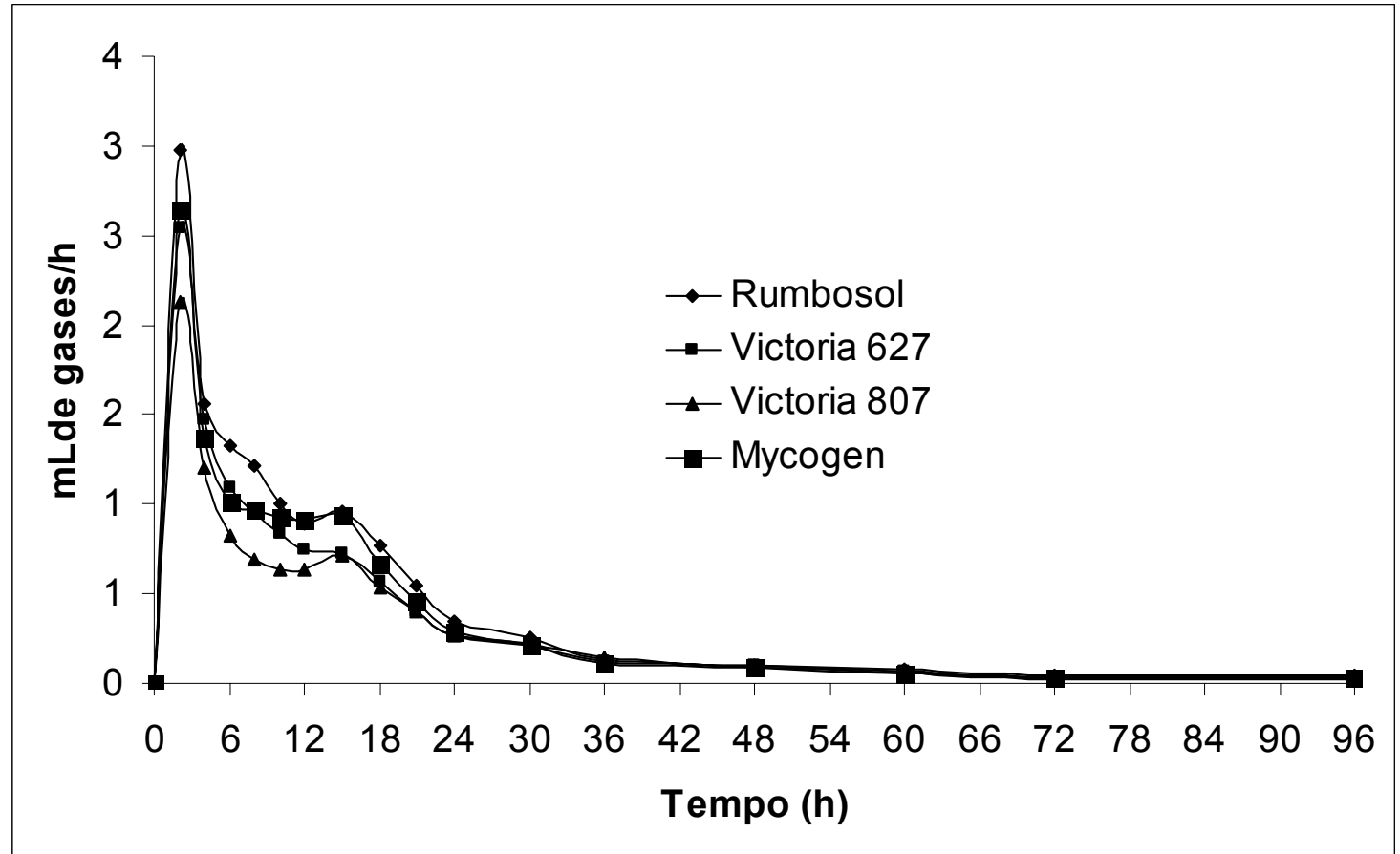

Figura 2. Produção de gases, por hora, das silagens de quatro genótipos de girassol.

Observa-se, na Fig. 2, que as maiores produções de gases foram obtidas no período entre zero e seis horas de fermentação, fato provavelmente ligado à fermentação dos carboidratos prontamente disponíveis. Entre os períodos de 12 e 18 horas, observa-se uma ligeira elevação na produção de gases por hora, que pode estar relacionada à fermentação dos carboidratos fibrosos. Desta forma, pode-se sugerir que a silagem do genótipo Rumbosol 91 é a que, provavelmente, possui maior concentração de carboidratos solúveis, pois apresentou a primeira curva do gráfico mais elevada. A degradabilidade da fração fibrosa da silagem do Victoria 807, possivelmente, é menor quando comparada às demais, que apresentaram maiores elevações na segunda curva do gráfico. Entretanto, vale ressaltar que grande parte das diferenças observadas na produção de gases, por hora, está relacionada às diferenças nas concentrações de EE das silagens, já que a gordura não apresenta contribuição significativa na produção de gases.

Os parâmetros da cinética de produção de gases e degradabilidade efetiva, determinados pelo modelo de France et al. (1993), referentes à matéria seca das silagens de girassol, encontramse na Tabela 4. 
Tabela 4. Potencial máximo de produção de gases (A) em mL/g de MS, tempo de colonização (TC) em horas e minutos, taxa de produção de gases $(\mu) \mathrm{em} \mathrm{mL} / \mathrm{g}$ de $\mathrm{MS} / \mathrm{h}$ e degradabilidade efetiva (DE) da matéria seca (\% de MS) para as taxas de passagem 2\%, 5\% e $8 \%$ das silagens de quatro genótipos de girassol

\begin{tabular}{lcccc}
\hline \multirow{2}{*}{ Parâmetros } & \multicolumn{4}{c}{ Genótipos } \\
\cline { 2 - 5 } & Rumbosol 91 & Victoria 627 & Victoria 807 & Mycogen 93338 \\
\hline A (mL/g de MS) & 125,46 & 102,62 & 91,67 & 108,85 \\
TC (h) & 1,40 & 0,10 & 1,39 & 1,69 \\
$\mu(\mathrm{mL} / \mathrm{g}$ de MS/h) & 0,073 & 0,066 & 0,066 & 0,080 \\
DE 2,0\%/h (\%) & 46,39 & 44,44 & 43,42 & 44,56 \\
DE 5,0\%/h (\%) & 43,26 & 43,02 & 40,48 & 41,21 \\
DE 8,0\%/h (\%) & 40,30 & 41,67 & 37,71 & 38,08 \\
\hline
\end{tabular}

Os potenciais máximos de produção de gases das silagens variaram de 91,67 a $125,4 \mathrm{~mL} / \mathrm{g}$ para os genótipos Victoria 807 e Rumbosol 91, respectivamente. Isto demonstrou que a silagem do genótipo Rumbosol 91 foi a que expressou a maior degradação ruminal, sem considerar $o$ tempo de permanência da digesta no rúmen. Maiores potenciais de degradação foram observados por Pereira (2003), com valores de $138,129,121$ e $119 \mathrm{~mL}$ para as silagens do genótipo M734 ensilado aos 100, 107, 114 e 121 dias após o plantio.

O menor tempo de colonização (TC) foi observado para o genótipo Victoria 627. Tal característica é desejável, pois está relacionada à presença de substratos prontamente fermentáveis e às características físicas e químicas da parede celular da amostra. Pereira (2003) observou maiores tempos de colonização para as silagens do genótipo M734 ensilado aos 100, 107, 114 e 121 dias após o plantio, com valores que variaram de 2,46 a 2,99 horas.

Blümmel e Ørskov (1993), ao trabalharem com os resultados obtidos por intermédio da técnica de produção de gases de Menke et al. (1979) e sacos de náilon, sugeriram que a taxa de fermentação $(\mu)$ e a taxa de degradação da matéria seca (c), respectivamente, proporcionaram altos coeficientes de correlação com o consumo. Dessa forma, os parâmetros de France et al. (1993), principalmente $\mu$, obtidos neste experimento indicam a possibilidade de que a silagem do genótipo Victoria 627 seria a mais consumida pelos animas.

A taxa de passagem de $2 \% / \mathrm{h}$ pode ser adotada para bovinos e ovinos em mantença; a de $5 \% / \mathrm{h}$ para vacas leiteiras de pequena produção $(<15 \mathrm{~kg}$ de leite/dia), bovinos de corte e ovinos em crescimento; e a taxa de $8 \% / \mathrm{h}$ para vacas produzindo acima de $15 \mathrm{~kg}$ de leite/dia, alimentadas com dietas mistas. $\mathrm{O}$ genótipo Rumbosol 91 apresentou as maiores DMS para as taxas de passagem de 2 e $5 \%$ com valores de 36,80 e $26,91 \%$. O maior valor para taxa de passagem de $8 \%$ foi observado para o genótipo Victoria 627, o que pode estar relacionado ao seu menor TC e a sua maior taxa de degradação $(\mu)$.

\section{CONCLUSÃO}

As silagens dos genótipos Rumbosol 91 e Victoria 627 destacaram-se das demais, por apresentarem o maior potencial de produção de gases e a maior taxa de produção de gases, respectivamente.

\section{REFERÊNCIAS BIBLIOGRÁFICAS}

BLÜMMEL, M.; ØRSKOV, E.R. Comparison of in vitro gas production and naylon degradability of roughage in predicting feed intake in cattle. Anim. Feed Sci. Technol., v.40, p.109-119, 1993.

FRANCE, J.; DHANOA, M.S.; THEODOROU, M.K.A model to interpret gas accumulation profiles with "in vitro" degradation of ruminants feeds. J. Theor. Biol., v.163, p.99-111, 1993.

GONÇALVES, L.C.; TOMICH, T.R.; PEREIRA, L.G.R. Produção e utilização de silagem de girassol. In: SIMPÓSIO DE FORRAGICULTURA E PASTAGENS, 1., 2000, Lavras. Anais... Lavras: UFLA, 2000. p.203-236.

GUIMARÃES Jr., R.; GONÇALVES, L.C.; MAURÍCIO, R.M. et al. Cinética de fermentação ruminal de silagens de milheto. Arq. Bras. Med. Vet. Zootec., v.60, p.1174-1180, 2008. 
JUNG, H.G.; VAREL, V.H. Influence of forage type on ruminal bacterial populations and subsequent in vitro fiber digestion. J. Dairy Sci., v.71, p.1526-1535, 1988.

MAURICIO, R.M.; MOULD, F.L.; DHANOA, M.S. et al. A semi-automated in vitro gas production technique for ruminan feedstuff evaluation. Anim. Feed Sci. Technol., v.79, p.321-330, 1999.

MAURÍCIO, R.M.; PEREIRA, L.G.R.; GONÇALVES, L.C. et al. Potencial da técnica in vitro semiautomática de produção de gases para avaliação de silagens de sorgo (Sorghum bicolor (L.) Moench). Rev. Bras. Zootec., v.32, p.10131020, 2003

MENKE, K.H.; RAAB, L.; SALEWSKI, A. et al. The estimation of the digestibility and metabolizable energy content of ruminant feeding stuffs from the gas production when they are incubated with rumen liquor in vitro. $J$. Agric. Sci., v.93, p.217-222, 1979.

MINSON, D.J. Forage in ruminant nutrition. San Diego, CA: Academic Press, 1990. 482p.

MOULD, F.L.; SMITH, T.; OWEN, E. et al. The relationship between DOMD and gas release estimated in vitro using the reading pressure technique system for four maize silages of different maturity. In: PROCEEDINGS of the British Society of Animal Science, 1999. Midlothian, Scotland. BSAS, 1999. p.150.

ØRSKOV, E.R.; McDONALD, T. The estimation of protein degradability in the rumen from incubation measurements weighted according to rate of passage. J. Agric. Sci., v.92, p.499-503, 1979.
PEREIRA, L.G.R. Avaliação do potencial forrageiro da cultura do girassol (Helianthus annuus L.) para produção de silagem. 2003. 88f. Tese (Doutorado) - Escola de Veterinária, Universidade Federal de Minas Gerais, Belo Horizonte.

REPORT of the protein group of the Agrucultural Research Council Working party, on the nutrient of ruminants. London. Commonwealth Agricultural Bureaux, 1984. $45 \mathrm{p}$.

ROSS, G.J.S. Maximun Likelihood Program. Harpenden, UK: Rothamsted Experimental Station, 1980.

SCHOFIELD, P.; PELL, A.N. Validity of using accumulated gas pressure readings to measure forage digestion in vitro: A comparasion involving three forages. J. Dairy Sci., v.78, p.2230-2238, 1995 .

THEODOROU, M.K.; WILLIAMS, B.A.; DHANOA, M.S. et al. A new gas production method using a pressure transducer to determine the fermentation kinetics of ruminal feeds. Anim. Feed Sci. Technol., v.48, p.185-197, 1994.

TILLEY, J.M.A.; TERRY, R.A. A two-stage technique for the "in vitro" digestion of forage crops. J. Brit. Grassl. Soc., v.18, p.104-111, 1963.

WILLIAMS, B.A. Cumulative Gas-production Techniques for Forage Evaluation. In: GIVENS, D. I.; OWEN, E.; OMED, H. M. et al. (Eds.). Forage Evaluation in Ruminant Nutrition. Wallingford (UK). CAB International. 2000. $475 p$. 